\title{
Viimeaikaisia näkymiä organisaation kehittämisestä
}

\author{
Pauli Juuti
}

Organisaatiot olivat modernin tuotteita. Postmoderniin siirtyminen heijastuu sekä käsityksiimme organisaatioista että niiden kehittämismenetelmistä. Luonnollisesti ei ole olemassa yhtä näkemystä postmodernista organisaatiosta sen paremmin kuin uusista organisaation kehittämisen menetelmistäkään. Tässä artikkelissa esitetään niistä joitakin keskeisimpiä. Monia näkökulmia on jätetty pois siksi, että niitä esitellään muissa tämän lehden artikkeleissa.

Olemme vuosituhannen vaihteessa todistamassa tapahtumasarjaa, jossa perinteinen tieteellinen näkökulma todellisuudesta on filosofiassa ja ihmistieteissä korvautumassa subjektiivisemmalla ja konstruktivistisemmalla todellisuuskäsityksellä. Keskeistä tässä muutoksessa on ollut kielen merkityksen uudelleenarviointi. Perinteisesti kielellä oli representaation luonne. Nyt yhä lisääntyvästi havaitaan kielen konstruoivan maailmaamme (Marshak 1998, 15). Tässä muutoksessa lähes kaikki oletukset, jotka ovat ohjanneet tieteellistä tutkimustoimintaa ja järkeämme, ovat kohdanneet voimakasta kritiikkiä (Gergen 1991, johdanto). Tieteessä käynnissä oleva paradigman muutos heijastuu käsityksiin organisaatioista ja organisaation kehittämisestä.

Perinteinen "tieteellisen" todellisuuskäsitys sai alkunsa Platonin ideaopissa. Luonnontieteellinen vallankumous (1500-luvulta alkaen) synnytti mekanistisen näkemyksen maailmasta ja ihmises- tä. Cartesiolainen ajattelutapa (1700-luvulla) synnytti dualistisen maailmankuvan, jossa tieteellisen ja järkevän toiminnan kohteeksi nousi ulkoinen, objektiivinen ja verifioitavissa oleva (Wright 1987, 9-10 ja 42). Objektiivisen ja subjektiivisen erottaminen kulminoitui loogisessa positivismissa. Looginen positivismi pyrki arvovapaaseen tieteeseen, joka oli joko formaalia (logiikka tai matematiikka) tai tosiasiallista (empiiristä) (Ehninger \& Hauser, 1984, 720-721).

Valistusaika pyrki luomaan yhden yhtenäisen tietojärjestelmän, joka nousisi sosiaalisen ja historiallisen yläpuolelle (Shotter 1996, 179). Modernismin projekti tähtäsi suureen kertomukseen, jossa tiedolla oli keskeisin sija. Tiedon avulla voitiin ratkaista kaikki ongelmat ja kaikki oli periaatteessa tiedettävissä. (Seidman \& Wagner, 1992, 2 -9). Tieteen saavutusten myötä lisääntyi edistysusko. Tiede otti tehtäväkseen selvittää kaikkien alojen lopullinen olemus. Kuitenkin järkevyyden, 
edistyksen, objektivismin ja lopullisen olemuksen etsinnän painottaminen johti lisääntyvään mekanistisuuteen myös ihmisten elämässä (Gergen 1991, 30-44).

$\mathrm{T}$ oisen maailmansodan jälkeen filosofiassa tapahtuneessa "lingvistisessä käänteessä“" tunnistettiin, ettei järkeä, merkityksiä, totuutta ja tietoa voi erottaa niistä lingvistisistä ja käytännöllisistä konteksteista, joissa ne syntyvät (Lynch 1993, johdanto).

\section{Jo 1960-luvulla Kuhn väitti, ettätiede kehittyy kuten politiikkakin. Paradigmansisälläolevattiedemiehet kehittävätparadigmaa, mutta eivätuudista sitä. Tiede- miehet,jotkatulevatvallitsevanparadigman ulkopuolella olevastatiedeyhteisöstä, saattavatkeksiäaivanuuden paradigman.Uudenparadigmanohjaamanatiedemiehet näkevätilmiöterivalossajakiinnittäväthuomiota eri asioihinkuinaikaisemmin}

(Kuhn, 1970, 11, 23, 93 ja 111).

1970-luvulla sosiologit ja antropologit tutkivat etnografisin menetelmin tiedeyhteisöjen toimintaa ja havaitsivat, että tiedeyhteisö konstruoi tuloksensa kielellisesti. He eivät havainnoi maailmaa sinänsä, vaan konstruoivat kieltä (havaintoaineistoja, oletuksia jne.), joiden avulla havainnot selitetään (Lynch 1993, 90-111).

Kuhnin ajattelua on osuvasti verrattu Wittgensteinin myöhäisfilosofiaan. Tieteessä, kuten arjessakin, nojaamme tradition tarjoamiin koodeihin, joita voidaan pitää "kielipeliä“ ohjaavana kenttänä. Paradigman sisällä olevat henkilöt ovat saman kielipelin jäseniä (Pihlström 1996, 16-17).

Nykyisin sosiaalitieteissä on yleisesti omaksuttu näkemys, ettei ihmisellä ole mahdollisuutta saada suoria objektiivisia havaintoja maailmasta ja ettei kellään ole olemassa etuoikeutettua asemaa sosiaalisen todellisuuden määrittämisessä (Epston \& White \& Murray 1996, 96). Kuhnin jälkeen on tieteen filosofiassa lisääntyvästi kiinnitetty huomiota historiaan ja tiedon sosiologiaan. Näissä näkökulmissa painottuvat kulttuuriset ja historialliset prosessit. Strukturalististen näkökulmien ohella viime aikoina tätä näkökulmaa on korostanut kieleen, tekstuaalisuuteen ja retoriikkaan sekä

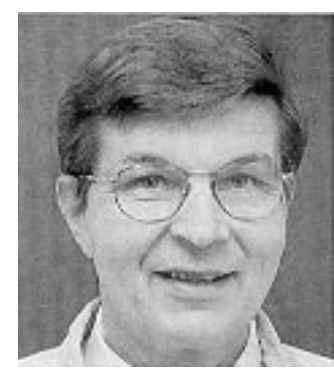

Pauli Juuti

semiotiikkaan liittyvä tutkimustoiminta $(\mathrm{McNa}$ mee \& Gergen 1996, johdanto).

\section{Nykyisinnähdään, etteitiede alaepäilystä (kutencartesiolaisuudessaoletettiin), vaan rïttüvän retorisenvoimanomaavan tarinantaikertomuksenomaksumisesta.}

Nykyisin omaksutun näkemyksen mukaan sosiaalista maailmaa voidaan parhaiten kuvata eräänlaisena jatkuvasti käynnissä olevana prosessina, jossa ihmiset itse rakentavat järjestystä ja rajoja kielen ja kielipelien avulla (Shotter 1993, 166). Tästä näkökulmasta sosiaalista maailmaa ei enää voi pitää yhden suuren kertomuksen sisällä olevana tai edes siihen pyrkivänä (Lyotard 1985, 7$10)$.

Jos sosiaalisen todellisuuden tunnistetaan syntyvän diskurssissa, on loogista asettaa käynnissä oleva diskurssi kriittiseen tarkasteluun. Tässä kriittisessä tarkastelussaFouCAuLt oli edelläkävijä. Foucaultille sosiaalinen todellisuus ja diskurssi eivät ole erillisiä, vaan sisäkkäisiä. Diskurssit ovat käytäntöjä, jotka systemaattisesti muokkaavat niitä objekteja, joista ne puhuvat. Diskurssit ovat ihmisten ilmaisemia käsityksiä asioista, jotka muokkaavat tiedon rakenteita, joiden kautta ihmiset toimivat. Foucaultille valta on aina läsnä kaikessa (muutoinkin kuin säännöissä tai kielloissa), se tuottaa diskursseja. Foucault pyrkikin tutkimaan niitä instituutiojärjestelmiä ja diskursiivisiä käytäntöjä, jotka paljastivat valtaa ja vallan suhdetta totuuteen. Myöhemmässä tuotannossaan omaksumansa genealogisen menetelmän tavoitteena oli tarkastella historiallisten ilmiöiden "periytymistä“. Genealogian tehtävänä oli toisinajattelemisen 
mahdollistaminen (dekonstruktio) (Husa 1995, 43 - 45).

Derridalle dekonstruktion keskeinen käsite olidifférance. Différance on jännite, joka syntyy sanotun ja vaietun väliin. Tämä jännite mahdollistaa ymmärtämisen ja uuden luomisen. Sanotun ja vaietun välissä on aina tilaa muille näkökulmille. Différance avaa Derridalle toiseuden, joka mahdollistaa erilaisuuden (Lax 1992, 71-72). Derrida avaa dekonstruktiolla kulttuurillemme väylän ulos Platonin ideamaailmasta (Hintsa 1998, 3233). Derridan, Foucaultin ja Lyotardin tapaiset ajattelijat ovat siirtäneet sosiaalitieteen strukturalismista poststrukturalismiin ja avanneet meille postmoderniksi kutsutun uuden tavan jäsentää yhteiskuntaa.

\section{ORGANISAATIOT OVAT MUUTTUNEET}

Organisaatioanalyysi oli vielä 1960-luvulle asti pettävän yksinkertaista. Organisaatioita tarkasteltiin modernin näkökulmasta byrokratian ihannemallin mukaisina struktuureina. Vaikka 1970-luku toi tullessaan kontingenssinäkökulman ja monimutkaisti organisaatioista omaksuttua näkökulmaa, se ei perustaltaan muuttanut niitä oletuksia, joille organisaationäkemykset perustuivat. Vasta kun ymmärtävä näkökulma ylsi organisaatiotutkimukseen saakka, alkoivat oletukset muuttua. Siihen asti melko yhtenäinen organisaatiotutkimuksen näkökulma alkoi hajaantua useiksi koulukunniksi. Näiden koulukuntien käyttämä kieli alkoi eriytyä. Koulukunnille oli yhteistä se, että niissä kritisoitiin byrokratian ihannemallia. Nykyisin organisaatiotutkimus on hajaantunut useisiin erillisiin koulukuntiin (Burrell 1997, 15-16).

Useiden erillisten koulukuntien esiintyminen sopii hyvin yhteen postmodernin kanssa, sillä postmoderni on pirstainen keinoympäristö, joka tuotetaan joko toissijaisilla kentillä (mediassa, tietoverkossa) tai nopeasti muuttuvissa episodeissa.

D ostmodernista näkökulmasta organisaation käsite on ongelmallinen. Organisaatiota ei enää voi pitää esimerkiksi jonkin paikan määrittämänä (esimerkiksi rakennuksena, tehtaana) tai rakenteena.

Postmodemissanäkökulmassaorganisaatiosta ontullutsosiaalistentoimijoiden kontekstuaalisissa diskursseissatuottamayhteisö,jokavaikuttaajäsentensä tapaan ymmärtääjatulkitamaailmaa.

Organisaatio on siis ne ympäristöt ja tilanteet, joissa toimijat sen puheellaan tuottavat (Gephardt \& Boje \& Thatchenkery 1996, 2). Clegg (1990, 177-206) oli ensimmäisiä, joka käytti postmodernin organisaation termiä viitatessaan uudenlaisiin verkostonomaisiin, joustaviin organisaatiomuotoihin, joita alkoi ilmetä markkinavoimien turbulenssissa (Calton \& Kurland 1996, 168).

Postmodernissa tieteen yhtenevä näkökulma ja kieli on hajonnut. Kulttuuri koostuu lukuisista melko itsenäisistä maailmankuvista ja merkitysjärjestelmistä. Modernissa tieteellinen menetelmä johti organisaationäkökulmien yhtenevyyteen ja validin näkökulman etsimiseen (Gephardt \& Boje \& Thatchenkery 1996, 6-7). Postmodernissa tiedettä pidetään diskurssina tai tarinakerrontana ja organisaatioiden nähdään olevan sosiaalisesti konstruoituna (Boje \& Fitzgibbons \& Steingard 1996, 60, 71).

Knen muovaa todellisuutensa kokemustensa ja havaintonsa avulla ymmärtämisprosessien kautta (Berger \& Luckman 1994). Jos uskomme Bergerin ja Luckmanin tavoin, että sosiaalinen todellisuus on ihmisen tuottama, voimme myös uskoa, että kykenemme halutessamme luomaan sosiaalisen todellisuutemme. Tätä tosin vaikeuttaa se, että ihminen kykenee tehokkaasti unohtamaan sen, että hän itse on muovannut oman todellisuutensa. Sosiaalisesti konstruoitu todellisuus siirretään ulkoisiin symboliympäristöihin, paradigmoihin tai skeemoihin. Nämä pitävät yhteisöä yllä, mutta samalla ne ehkäisevät innovaation. Postmodernissa merkitykset astuvat keskiöön (Binzagr \& Manning 1996, 251-255).

Postmoderni tunnistaa symboliympäristöjen konstruktiivisen luonteen ja kulttuurien moninaisuuden. Postmoderni johtaakin relativismiin, joka on parhaimmillaan muiden näkökulmien suvait- 
semista ja omien näkökulmien muuttamista, reflektion, refleksion ja dekonstruktion kautta.

\section{Postmodemissaorganisaatiotapidetäänsosiaalisena konstruktiona,jokatuottaaomankielensäja kielipelinsä.Toiminnanoikeutusonorganisaatiossa yhteisestiomaksutussadiskurssissa.}

Diskurssia voidaan muuttaa reflektion kautta. Moderni diskurssi sisälsi lineaarisuuden ja edistyksen oletukset. Luodessaan refleksiivisen keinon muuttaa tätä diskurssia Derrida tarttui eron (differance) käsitteeseen. Sillä on kahtalainen luonne. Ero sekä jakaa että yhdistää. Differance luo illuusion läsnäolosta. Ihminen tulkitsee holistisen ja subjektiivisen tietoisuutensa (tietoisen itsensä) kautta esillä olevan. Kuitenkin esillä oleva aina sisältää myös kätketyn, poissa olevan. Lisäksi tietoisuus välittyy aina epäsuoralla tavalla "tulkittuna". Tällä tavalla "toinen" on aina mukana puheessa ja toiminnassa. Derrida korvaakin modernin subjektin käsitteen toimijalla. Subjekti oli itsenäinen kokonaisuus, kun taas toimija on suhdejoukko. Subjekti ei ole enää itseohjautuva, vaan sopiva tila diskurssissa (Hassard 1996, 51- 53).

Kiinnittämällä huomiota tekstien monimerkityksellisyyteen (sanojen ja tekstien indeksuaalisuuteen) dekonstruktio siirtää meidät pois yleisistä totuuksista kohden sanojen leikkiä, todellisuuksien erilaisuutta ja pirstaleisuutta. Dekonstruktio hajottaa "normalisoivan" diskurssin. Diskurssi strukturoi yhteisöä, koska sanoilla on aina niihin edeltäkäsin liitetty merkityksensä. Dekonstruktio muuttaa näitä ennalta annettuja merkityksiä. Derrida on osoittanut, kuinka sanat ja vertauskuvat sisältävät voimakkaita ennakko-odotuksia. Vertauskuvat sisältävät myös vahvan myytin yhtenevyydestä, harmoniasta ja järkevyydestä. Samalla ne luovat mielikuvan yhtenevään käsitejärjestelmän neutraalisuudesta ja sen perusteella toteutetun toiminnan oikeutuksesta (Bradshaw 1996, 100101).

Diskurssi, dekonstruktio ja mielikuvat ovat postmodernien organisaatioiden keskeisiä käsitteitä. Olemme yhä lisääntyvässä määrin havahtuneet siihen, että luomme organisaatiot omissa mielikuvissamme. Onkin kysyttävä, miksi olemme luo- neet modernin organisaation hierarkioineen, virkoineen ja valvontamalleineen sekä yksilöllisen uran mahdollisuuksineen. Ehkä siksi, että organisaatiot ovat vastauksia ihmisten rajallisuuteen liittyviin ongelmiin. Ne tarjoavat jatkuvuutta (Barry \& Hazen 1996, 147 - 148) ja mielikuvan ihmisen liittymisestä itseään suurempaan kokonaisuuteen sekä tunteen, että elämällä ja toiminnalla on merkitystä. Lisäksi ne asettavat jokaisen "omalle" paikalleen turvallisesti ja "oikeudenmukaisesti“.

Kaikki tämä tapahtuu kuitenkin modernin "tieteellisessä“ ja "järkevässä“ viitekehyksessä, jonka mekanistinen luonne on yhä selvemmin alettu tiedostaa. Samalla on alettu etsiä uusia mielikuvia organisaatioille ja ihmisen olemassaololle.

$\mathrm{P}$ ostmoderni onkin sopiva "alusta" uusien mielikuvien etsimiseen. Postmoderni ympäristö asettaa meidät liikkuvaan ja epäjatkuvaan tilaan, jossa selviäminen vaatii jatkuvasti uudistamaan mielikuviamme, "hyppelemään maailmasta toiseen“. Keinoympäristö tarjoaa kuitenkin ennennäkemättömät mahdollisuudet dekonstruktioille ja liikkuvien mielikuvien luomiselle.

\section{MORGANIN VERTAUSKUVAT ORGANISAATIOSTA}

\section{ja mielikuville perustuva organisaation kehittäminen}

Morgan loi kuuluisan vertauskuville perustuvan mallinsa vuonna 1980 ja kansanomaisti sitä organisaation muutokseen paremmin sopivaksi vuonna 1986 (Morgan 1980, 608 ja Morgan 1986). Morganin malli perustuu vertauskuville. Muutos Morganin mallissa on vertauskuvien avulla luotu dekonstruktio.

$\mathrm{V}$ ertauskuvia voidaan pitää dekonstruktiivisina sikäli, että ne yhdistävät, vaikka ne ovat erilaisia. Vertauskuvat siirtävät sanoja ja merkityksiä ympäristöstä toiseen, jossa ne eivät tavallisesti ole esiintyneet. Vertauskuvat käsittelevät erilaisia asioita ikään kuin ne olisivat yhteneviä (Döving 1996, 185). 
Vertauskuvia voidaan pitää pelkästään kirjallisina apukeinoina tai kuvallisena ilmauksena, kuten perinteisessä tieteessä nähdään. Kuitenkin voidaan kysyä, onko kieli perimmältään vertauskuvallista. Jos oletetaan, että kieli on perimmältään vertauskuvallista, oivalletaan, että kieli on syntynyt vahvojen kokemusten symboloimisprosessien tuloksena historian eri vaiheissa. Kieli on kuin elävä kasvi. Siinä on osia eri kasvun vaiheista. Vanhat kokemukset on vertauskuvallistettu. Vertauskuvat eivät ole ikkuna maailmaan, vaan ne ovat artefakteja ihmisten luomista viitekehyksistä (ymmärtämispyrkimyksistä eri tilanteissa). Kieli muodostuu elävistä ja kuolleista vertauskuvista. Kuolleet vertauskuvat ovat niin vanhojen kokemusten muistoja, että niitä pidetään neutraaleina kielen osina. Elävät vertauskuvat tuovat mieleemme sen kokemusympäristön, johon ne viittaavat (Chia 1996, 127-129).

Kulleiden vertauskuvien merkityssisältöjen Tässä dekonstruktiivisessa prosessissa avataan tähän asti neutraaleilta ja itsestään selviltä näyttäviä ilmauksia ja käsitteitä sekä haetaan niihin uusia tulkintoja etsimällä niihin liittyviä kätkettyjä jännitteitä. Samalla aletaan puhua siihen asti vaietusta. Tällainen dekonstruktio ilmaisee perinteisten tulkintojen riittämättömyyden johtaen meidät lähemmäs niitä kokemuksia, joissa vertauskuvat syntyivät.

\section{Dekonstruktioorganisaatioistajanüssäkä̈tetystä kielestäomaasurriamahdollisuuksiakehittääjaundis- taaorganisaatioitajajohtamista (Chia 1996, 140).}

Voimmekin päätyä näkemykseen, että kieli on täynnä vertauskuvia. Niiden avulla ymmärrämme tilanteita ja konteksteja, joissa olemme. Vertauskuvien avulla siirrämme tutun ympäristön tai tilanteen merkitykset outoon ympäristöön. Näin luomme uusia merkityksiä. Vertauskuvilla onkin vapauttava vaikutus, ne tuovat uutta sisältöä ja merkitystä vanhaan ja antavat sisällön oudolle. $\mathrm{Ne}$ ovat ymmärryksen ja oppimisen välineitä. Vertauskuvien avulla voimme nähdä maailman uudesta näkökulmasta. Vertauskuvat yhdistävät kahden erilaisen "maailman" luomalla analogoita, tai muovaamalla sillan kahden maailman välille kielellisen yhtenevyyden tai olemukseen viittaavaan mielikuvallisen yhteneväisyyden avulla (Grant \& Oswick 1996, 1- 8).

Vertauskuvien avulla ihmisiin voidaan vaikuttaa. Ne luovat struktuuria ajatteluun. Lisäksi jokapäiväiset itsestään selvinä pidetyt vertauskuvat ovat niin tavanomaisia, että niitä käytetään automaattisesti. Niiden taustalla olevaa äänetöntä tietoa ei edes tulla ajatelleeksi, saatikka asettaneeksi kyseenalaiseksi. Vertauskuvia onkin vaikea asettaa kyseenalaiseksi. Vertauskuva luo ajattelulle raamit ja samalla se asettaa arvioinnille perusteet (Mangham 1996, 27-29).

Vertauskuvien valta perustuu siihen, että ne nimeävät, viitekehystävät ja määrittävät ongelmanasettelun. Lisäksi ne luovat rakenteen, jota pitkin ongelmanratkaisuprosessissa ja kysymyksen asettelussa edetään. Ne asettavat päämääriä ja luovat hyväksi tai rangaistavaksi koetun rajat. Vertauskuvat ohjaavat mielenkiinnon tiettyihin tulkintoihin tilanteessa ja näin suuntaavat toiminnan tietyllä tavalla (Dunford \& Palmer 1996, 96-97).

$\mathrm{M}$ organ lähtee omien organisaation vertauskuviensa kehittelyssä sosiaalisesta konstruktivismista. Hän pitää vertauskuvia ja mielikuvia sosiaalisina konstruktioina, joita ihmiset aktiivisesti tuottavat ja uusintavat. Samalla hän näkee ihmisten jäävän kielen "vangeiksi“. Hän toteaa Foucaultin osoittaneen, että kieleen sisältyy valtarakenteita, jotka strukturoivat arkea: "vaikka kykenemmekin tuottamaan sosiaalisen maailman, sosiaalista todellisuutta on usein vaikea murtaa. Niinpä ihmistä tulee usein passiivisia ‘ääniä’ pikemminkin kuin 'puhuvia subjekteja', jotka muovaisivat uudelleen sosiaalisia konteksteja“" (Morgan 1993, 274).

Morganin mukaan mielikuvilla ja vertauskuvilla on potentiaalia ihmisen vapautuksessa, koska niiden avulla voidaan muuttaa viitekehyksiä ja saada aikaan transformaatiota. Näin siksi, että Morganille vertauskuvat eivät ole vain kielellisiä ilmauksia, vaan pääasiallisia keinoja, joiden avulla ihmiset muovaavat suhteen maailmaan. Tuota maailmansuhdetta voidaan muuttaa vertauskuvia muuttamalla. Mielikuvitus vapauttaa meidät vanhoista vertauskuvista. Mielikuvitus auttaa meitä 
ymmärtämään tilanteet eri tavoin. Eri vertauskuvat luovat erilaisia näkemyksiä tilanteista, saattavat meidät erilaisiin suhteisiin maailmaan nähden.

Mielikuvienjoustavamuuttaminen lisä̈ihmistenkykyä jatkuvaanitseorganisoitumiseen, jotaMorganpitää organisoitumisenparhaanavaihtoehtona

(Morgan 1993, 3 - 17, 275 - 277).

$\mathrm{M}_{8}$ organ esittelee seuraavat vertauskuvat organisaatioista:

$\begin{array}{ll}1 & \text { organisaatio "koneena" } \\ 1 & \text { organisaatio "eliönä“" } \\ 1 & \text { organisaatio "aivona" } \\ 1 & \begin{array}{l}\text { organisaatio "teatterina" } \\ 1\end{array} \\ \text { organisaatio "poliittisena järjestelmänä“ } \\ 1 & \begin{array}{l}\text { organisaatio "psyykkisenä vankilana" } \\ \text { (Morgan, 1986). }\end{array}\end{array}$

"KoNEMALLI"liittyy luonnontieteellisen näkökulman omaksumiseen. Tieteellisen ajattelun oikeellisuutta symboloi se, että kyettiin rakentamaan laitteistoja, jotka helpottivat ihmisen työtä ja auttoivat hänen pyrkimyksissään kahlita luontoa omien päämääriensä käyttöön. Luonnontieteessä kehitetty ajattelumalli sisäistettiin myös muihin elämänalueisiin, kuten yhteiskuntatieteisiin ja organisaatioajatteluun. "Konemalli“" organisaatiosta noudattaa jokseenkin samoja periaatteita, joiden varassa mekaanisesti toimiva kone on toteutettu. "Konemalli“" organisaatioihin sovellettuna kehitti vähitellen oman standardoidun sosiaalisen koodistonsa ja kielensä sekä oman erityisen sosiaalisen rakenteensa sekä normistonsa (Morgan, 1986, 11- 35).

"ElIÖMALLISSA" organisaatioita pidetään systeemeinä, jotka ovat ympäristössään, josta ne ovat riippuvaisia ja jonka avulla ne voivat tyydyttää moninaiset tarpeensa. Systeemiteorian mukaan ei ole olemassa yhtä parasta tapaa organisoida (Morgan, 1986, 39-76). Esimerkiksi Mintzberg jaottelee organisaatiotyypit viiteen sen mukaan, millaisessa ympäristössä ne ovat (Mintzberg, 1983).

"Aivomalli" organisaatiosta perustuu oppimaan oppimisen periaatteiden (kaksivaiheisen oppimi- sen) ja holografiaan liittyvän kaikkien osien keskinäisen riippuvuuden periaatteiden yhdistämiselle. "Aivomallissa" tunnistetaan jokaisen yksilön olevan sekä osa kokonaisuutta että ainutkertaisen yksilön (sana holon viittaa sekä kokonaisuuteen että yksilöön). Lisäksi tarvitaan kapasiteettia erilaisten vaihtoehtojen kokeiluun. Mikäli nämä olosuhteet ovat olemassa, voi organisaatio saavuttaa samanlaisen joustavan tavan käsitellä erilaista tietoa ja sopeutua kuin aivotkin (Morgan, 1986, 77-109).

“TEATterimAlli"viittaa kulttuurinäkökulmaan, jossa organisaatiota pidetään merkitysjärjestelmänä. Tiettyyn symboliympäristöön ja myytistöön liittyy tietynlainen mentaliteetti eli tapa hahmottaa maailmaa tiedollisella, elämyksellisellä ja toiminnallisella tasolla (Morgan, 1986, 131-140).

Ajatus, että ihmiset luovat oman todellisuutensa vuorovaikutuksen kautta, voidaan ilmaista muodossa, että ihmiset ovat omien sosiaalisten vuorovaikutussuhteidensa kautta luomiensa merkitysjärjestelmien "vankeja”. Organisaatioita voidaankin pitää psyykkisinä "vankiloina", koska organisaatioiden merkitysjärjestelmät luodaan tietoisissa ja tiedostamattomissa prosesseissa, joiden seurauksena ihmiset jäävät tiettyjen mielikuvien, ajatusten ja toimintatapojen vangeiksi. Alitajuiset prosessit toimivat sekä yksilö että ryhmätasolla, kuten Bion on osoittanut. Näillä on merkitystä tulkittaessa organisaatiossa tapahtuvia ilmiöitä. (Bion, 1961 ja Morgan, 1986, 19 - 222, Juuti 1995).

Toisessa yhteydessä Morgan on luonut kuusivaiheisen luokittelun organisaatioista (malli 1 - malli 6) organisaation mekanistisuuden / orgaanisuuden perusteella (Morgan 1989, 64-67). Hän puhuu myös lukuisista muista vertauskuvista, kuten "RÖNSYORGANISAATIOSTA“ ja “HÄMÄHÄKKITEHTAASTA“"(Morgan 1993, 63 - 91).

Morganin vertauskuvat auttavat ymmärtämään organisaatioita tietyllä tavalla. Luomme tilanteiden ja sanojen merkityksen suhteessa siihen laajempaan viitekehykseen tai skeemaan, johon ne liittyvät. Ymmärrämme abstrakteja ilmiöitä ottamalla käyttöömme konkreettisempia kokemusra- 
kenteita (mielteitä) ja ymmärrämme ne vertauskuvallisesti. Tässä suhteessa Morganin vertauskuvat auttavat hahmottaman ihmisten tapoja suuntautua organisaatioihin. Valitettavasti Morgan ei analysoi niitä tapoja, joilla ihmiset suuntautuvat organisaatioihin ja maailmaan tarkemmin. Hän ei analysoi ihmisten maailmankuvien ja organisaatioista omaksuttujen vertauskuvien suhdetta (Manghan 1996, 21-25).

Morganin vertauskuvat auttavat uusien mielikuvien luomisen lisäksi myös teoreettisina konstruktioina ja tutkimustyössä luokittelun apuvälineenä (Clegg \& Gray 1996, 80-81). Tässä tarkoituksessa ne vähentävät aineistoa. Samalla ne auttavat näkemään omien rajojen ylitse (Inns \& Jones 1996, 111).

\section{FOUCAULT JA \\ ORGANISAATION MUUTOS}

Organisaatiokirjallisuudessa ollaan viime aikoina yhä lisääntyvässä määrin kiinnostuttu Foucaultin ajattelutavasta. Foucaultin ajattelutapa on monimutkaista ja monitasoista ja hänen tulkintansa organisaatioihin ei ole aina yksiselitteistä. Lisäksi Foucaultin ajattelussa on kaksi erillistä vaihetta, joita kutsutaan varhaisemmaksi ja myöhäisemmäksi vaiheeksi.

Varhaisempaa vaihetta kuvastaaarkeologinen metodi. Arkeologisessa metodissa Foucault katsoo totuuden muodostuvan väittämistä diskurssissa. Tässä vaiheessa Foucault painottaa diskurssin itsenäistä luonnetta. Arkeologisessa vaiheessa Foucault pyrki paljastamaan niitä sääntöjä, jotka säännöstivät ja hallitsivat sosiaalista käytäntöä, vaikka toimijat eivät niitä tiedostaneetkaan (Burrell 1998, 15-17). Myöhäisemmässä vaiheessa Foucault käytti genealogista metodia. Genealogialla on juurensa Nietzschen samannimisessä kirjassa (McKinley \& Starkey 1998, 1). Genealogia asettuu vastustamaan perinteistä historiaa ja pyrkimystä etsiä taustalla olevia lainalaisuuksia. Genealogiassa ollaan kiinnostuneita ennalta odottamattomasta ja pinnallisesta. Siinä oletetaan todellisuuden esiintyvän sellaisenaan. Genealogisessa ollaan kiinnostuneita yksityiskohdista ja niiden merkityksestä (Burrell 1998, 17-22).
$\mathrm{F}$ oucaultille valtasuhteet ovat diskurssissa ja tiedossa. Totuus ja tieto ovat keinoja, joilla yhteiskuntaa johdetaan. Foucault analysoi organisaatioiden syntyaikoja ja normalisointiprosesseja modernin alussa. Hän paljastaa, että tehokkuuden, oikeudenmukaisuuden tai inhimillisyyden fasadin takaa paljastuu vallan ja tiedon keskittymiä (McKinlay \& Starkey 1998, 1-2).

Organisaatioiden kannalta ehkä kiinnostavin vertaus on Foucaultin panoptisen (Foucault 1977, 199-228) ja organisaatioiden välillä. Foucault käyttää Benthamin panoptinen-käsitettä. Benthamille panoptinen oli keino ohjata ihmisiä itsekontrolliin, se oli demokratian toteutumisen väline (McKinley \& Starkey 1998, 3). Benthamin panoptinen oli ympyrän muotoinen rakennus, jossa oli keskusvalvontatorni, josta kaikkia asukkaita (vankeja) voitiin tarkkailla ilman, että asukkaat näkivät tarkkailijan. Foucault analysoi panoptista vallan kannalta (Burrell 1998, 19).

\section{Panoptisenorganisaation rakentuminen liittyy toisaalta hierarkkisenorganisaationsyntyynjatoisaaltasiihen tapaan, jolla 1800-luvultaalkaen ihmisiäon koulutettu tarkkaanajanjatoiminnan kontrolliin.}

Mekanistinen "koneajatus" levisi ihmisten kasvatukseen ja näkökulmaan organisaatioista. Mm. koululaisten istuma-asennot ja sotilaiden askeltamistapa marssiessa sekä koulutuksessa käytetty minuutin tarkka ohjaus ovat esimerkkejä tästä tarkkuuteen kasvatuksesta. Mekanistisissa organisaatioissa ihmisistä tulee tapauksia, joita mitataan, arvioidaan ja vertaillaan. Ihmisten väliset erot havaittiin, mutta vain poikkeuksina normista. Normin loivat asiantuntijat, kuten lääkärit, opettajat, papit, juristit jne. (Burrell 1998, 19).

Panoptisen vaikutus ei niinkään ollut sen kontrolloivassa vaikutuksessa kuin siinä, että ihmiset alkoivat kontrolloida omaa toimintaansa ajatellen, että heitä jatkuvasti tarkkaillaan ja valvotaan. Panoptinen johti itsekontrolliin (Savage 1998, 68). Myöhemmässä tuotannossaan Foucault kiinnitti enemmän huomiota siihen, miten valta kutsuu esiin uudenlaisia subjektiivisuuden muotoja, millä menetelmillä "itsesuhteita pyritään kehittämään harjoituksissa, joiden avulla itse asetetaan itsen 
tutkimuskohteeksi, ja käytännöissä, jotka mahdollistavat oman olemistavan muuttamisen" (Foucault 1998, 136). Modernin valtasuhteet vaativatkin subjektin rakentumista eettisyyden muodostumisen prosesseissa.

Ihmiset määrittävät kasvunsa kuluessa itsensä tietoisella tavalla "olemassaolon loistoon", eettisiksi henkilöiksi. Eettinen käyttäytyminen on seurausta tietyssä yhteisössä omaksutusta yhteisymmärryksestä, miten tulee toimia sen yhteisön jäsenenä. Subjektivoitumisessa henkilö määrittää ihanteekseen ja käyttäytymisohjeekseen tietynlaisen olemassaolon mallin, joka toimii hänen moraalisena päämääränään. Tämä vaatii ihmistä tarkkailemaan, arvioimaan ja kehittämään omaa toimintaansa (Starkey \& McKinley 1988, 234).

$\mathrm{S}$ ubjektivoituminen yhdistettynä kurinalaiseen koitavuutta. Kurinpidollisten tekniikoiden tavoite on normalisointi, tiettyyn paikkaan ja tilanteeseen liittyvä subjektin diskursiivinen kiinnittäminen (Clegg 1998, 35).

Työntekijöiden osalta subjektivoituminen toteutuidressageen yhdistettynä. Dressage voitaneen kääntää hevosen kesyttämiseksi ja kurinpidoksi. Foucaultin mielestä 1800-luvulla tapahtunut suurten organisaatioiden synty johti dressageen työvoiman osalta. Heidän tilaansa, toimintaansa ja työtään valvottiin ja johdettiin tavalla, jota voidaan kutsua dressageksi. Tayloristinen johtamistapa pyrki valvomaan työn suorittamistapaa yksityiskohtaisesti, mutta se pyrki myös poistamaan poikkeavuudet (Jackson \& Carter 1998, 54-59).

$\mathrm{J}$ ohtajien osalta subjektivoituminen ja kurinpito toteutui toisen maailmansodan jälkeen käyttöönotettujen johtamismenetelmien seurauksena. Niissä tulosyksiköiden ja taloudellisten tunnuslukujen käyttö lisäsivät jokaisen toiminnan läpinäkyvyyttä. Sloan (General Motorsin toimitusjohtaja) täydensi Taylorin periaatteet käyttämällä tulosyksikköorganisaatiota ja tunnuslukuihin perustuvaa johtamista. McNamara käytti samanlaisia periaatteita toimiessaan Fordin talousjohtajana. Ne toimivat moitteetta 1950- ja 1960-luvuilla, mutta olivat johtaa katastrofiin 1970-luvulla lisäänty- neen kilpailun oloissa. Talousasioiden liiallinen painottaminen johti vain kustannussäästöihin, eikä markkinoiden vaatimiin uusiin innovaatioihin. Vasta japanilaisen kilpailun tulon jälkeen tajuttiin, ettei ollut varaa liialliseen byrokratiaan, joka pyrki valvomaan toimintoja. Sen sijaan oli saatava aikaan sitoutumista (McKinlay \& Starkey 1998, 111-123).

Geneen vei tulosyksikköidean huippuunsa ITT:ssä 1970-luvulla. Hänen mukaansa numeroita oli helpompi lukea kuin tekstejä. ITT käyttikin detaljoitua taloussuunnittelujärjestelmää, jossa jokaiseen vuoden ajankohtaan liittyi tietyt toimenpiteet. Hierarkkinen seuranta lisäsi toimintojen läpinäkyvyyttä, joka kulminoitui tulosyksiköiden johtajien kuukausikokouksissa, joita voidaan pitää eräänlaisina "koetilaisuuksina“. ITT:n tapausesimerkki kuvaa, kuinka panoptinen ansa toimii myös organisaation ylätasoilla (Hopper \& Macintosh 1998, 126-144).

$\mathrm{T}$ ietointensiiviset organisaatiot ja uudenlaiset organisaatiot ovat pyrkineet muuttamaan ajattelutapojaan, rakenteitaan ja kulttuuriaan joustavaksi verkostoksi. Ovatko ihmiset näissä organisaatioissa kyenneet välttämään panoptisen ansan? Joidenkin tutkimusten mukaan näissäkin organisaatioissa vallitsee panoptisia piirteitä, joskin lievemmässä muodossa. Niissä näyttäisi esiintyvät subjektivoitumista yhdistettynä pelkoon organisaation taloudellisen tuloksen epäonnistumisesta. Uusien organisaatiomuotojen yleistyessä foucaultilaisen tarkastelun painopiste siirtyneekin panoptisen tarkastelusta Foucaultin myöhäisemmän vaiheen subjektivoitumis-käsitteen tarkasteluun (Deetz 1998, 151-169 ja McKinlay \& Taylor 1998 , $173-189)$.

\section{USEIDEN PARADIGMOJEN YHDISTÄMINEN DEKONSTRUKTIONA:}

\section{Organisaation syvällinen mu utos}

Vertauskuvien käytön ja genealogisen analyysin ohella organisaation muutosta voidaan postmo- 
dernista näkökulmasta pyrkiä toteuttamaan mm. yhdistämällä samaan muutosprosessiin useista kehittämisparadigmoista otettuja elementtejä. Valituissa paradigmoissa voidaan myös tukeutua modernin oletuksiin kiinnittyneisiin näkökulmiin. Kehittämisparadigmojen yhdistämisen avulla pyritään saamaan aikaan paradigmallinen hyppäys organisaatiossa omaksutuissa ajattelutavoissa. Tällaista hyppyä kutsutaanorganisaation transformaatioksi (OT) taiorganisaation syvälliseksimuutokseksi (Juuti \& Lindström 1995)

Organisaation syvällisellä muutoksella (OT) tarkoitetaan toisen sukupolven organisaation kehittämistä, joka tähtää siihen, että organisaatio kykenee hahmottamaan itsensä uudella tavalla (Fletcher 1990, 9). OT:ssä koko ajattelun ja sitä ylläpitävän symbolisen kentän perustarinasto, kieli ja kulttuurinen mentaliteetti muuttuvat. Tämä luo perustan uudenlaisen sosiaalisen järjestyksen synnylle (Levy \& Merry 1986, 9-19).

$\mathrm{P}_{\mathrm{r} a \mathrm{~d}}$ orras \& Silvers ovat esittäneet kolmen eri paradigman yhdistämistä organisaation syvällisen muutoksen aikaansaamiseksi. Tätä mallia on myös Suomessa joissakin organisaatioissa käytetty (Juuti \& Lindström 1995). Porraksen ja Silversin mallissa uuden vision aikaansaamiseen liittyvät muunnosprosessit yhdistyvät perinteisen organisaation kehittämisen malleihin ja kognitiiviseen muutokseen (Porras \& Silvers 1991, 53). Porraksen ja Silversin mallin voidaan myös nähdä sisältävän kolmen eri tasoisen "puheen" tulkintaa ja muutosta: 1) arjen "puheen“, jota käytetään työkalunomaisesti, 2) viitekehystävän "puheen“, joka luo viitekehyksen arjen käytännöille ja 3) myyttisen "puheen“, joka luo perustan viitekehyksille (Marshak 1998, 22-25). Konferenssimenetelmässä käytetty demokraattinen dialogi tapahtuu arjen "puheen" tasolla, luoden uusia viitekehyksiä. Työyhteisössä toteutetut projektit etenevät uusista viitekehyksistä uudenlaisen arjen "puheeseen". Kulttuurin kartoitus etenee myyttisen "puheen" tasolle mahdollistaen uusien viitekehysten syvällisen ankkuroinnin. Seuraavaksi esitetään Suomessa käytetyn sovelluksen kehittämisparadigmojen taustoja.

\section{Demokraattinen dialogi}

Organisaation syvällisen muutoksen sovellutuksissa on lähdetty liikkeelle Gustavsenin kehittämän toimintatutkimuksellisesti suuntautuneen 'demokraattinen dialogi' -menetelmän avulla. Demokraattisessa dialogissa painotetaan kieleen ja merkityssisältöihin liittyviä näkökantoja. Kieltä pidetään sosiaalisen todellisuuden muodostumisen areenana.

Demokraattisessa dialogissa kehittäminen etenee toimintatutkimuksen ideologian mukaan kehittämisprosessina. Toimintatutkimuksessa pyritään toisin kuin asiantuntijoiden ohjaamassa muutoksessa osallistamaan toimijat muutoksen suunnitteluun ja toteutukseen. Jos tarvitaan ulkopuolista apua, ongelman ratkaisusta tulee yhteinen prosessi, jossa kaikki oppivat (Weisbord, 1988, 9 11). Toimintatutkimus on tutkimusstrategia, jossa käytetään tieteellisiä menetelmiä käytännöllisten ongelmien ratkaisemiseksi tavalla, joka luo uutta sosiaalitieteellistä tietoa ja uusia teorioita (Elden \& Levin, 1990, 127). Toimintatutkimuksessa tutkimuskohteesta on tullut aktiivinen osanottaja ja tutkija pyrkii käyttämään ymmärtävän tieteen traditiota hyväkseen (van Beinum, 1993, 191).

Toimintatutkimusta on käytetty työelämään liittyvissä kehittämishankkeissa mm. Skandinaviassa toteutetuissa työelämän demokratisointiin liittyvissä kehittämispyrkimyksissä. Demokraattisen dialogin laajamittainen kokeilu tapahtui Ruotsissa toteutetun LOM -projektin (Eijnatten, 1993, 17 ja Arbetsmiljöfonden, 1990, 7) ja vastaavanlaisen Suomessa toteutetun Johtaminen, organisaatio ja yhteistoimintaohjelman (JOY -hankkeen) yhteydessä (Juuti \& Varjoranta 1993). Johtaminen, organisaatio ja yhteistoimintaohjelman puitteissa toteutettiin työpaikkakohtaisia eri muotoisia tutkimus- ja kehittämishankkeita Ruotsissa noin 150 työpaikalla (Gustavsen, 1990, 123-126). Kehittämisen kohteena oli erilaisia työpaikkoja sairaaloista autotehtaisiin (esimerkiksi Döhrming \& Gustafsson, 1990).

JOHTAMINEN, ORGANISAATIO JA YHTEISTOIMINTA -hankkeessa keskusteluilla on keskeinen merkitys. Niinpä 
projektista muodostuukin eräänlaiseksi useiden keskustelufoorumien ja useiden verkostojen koosteeksi (Arbetsmiljöfonden, 1990, 11).

Johtaminen, organisaatio ja yhteistoiminta -hankkeen ja hankkeessa käytyjen keskustelujen tavoitteena on luoda työpaikalle tehokas, opettavainen ja itsestään ohjautuvasti etenevä kehitysohjelma, joka perustuu kaikkien osallistumiseen (Räftegård, 1990, 14).

Johtaminen, organisaatio ja yhteistoiminta -ohjelmassa käytetään pääosin neljää toimenpidettä em. tavoitteen saavuttamiseksi: Ensinnäkin kolmen tai neljän yrityksen edustajista koostuvien “joukkueiden” välistä yhteistoimintaa, toiseksi useiden yritysten edustajista koostuvaa verkostoa, kolmanneksi kullakin työpaikalla tapahtuvaa laajapohjaiselle osallistumiselle perustuvaa kehittämistyötä ja neljänneksi käytetään tutkijoita tukemaan työpaikkakohtaisia kehittämishankkeita. Kehittämistyön apuvälineenä käytetään konferensseja, joiden avulla varmistetaan laajamittainen osallistuminen työpaikkakohtaisissa kehittämishankkeissa ja joiden avulla useiden yritysten välinen yhteistyö voidaan toteuttaa (Gustavsen, 1990, $15)$.

Kommunikatiivisuuden periaate on lainattu em. ohjelmiin Habermasin ideaalisen puhetilanteen teoriasta. Habermasille ihanteellisen puhetilanteen ehtojen täyttyminen edellyttää totuudellisuuden, oikeellisuuden ja ymmärrettävyyden vaateiden täyttymistä. Mikäli nämä vaateet täyttyvät, tulee puhetilanteessa esille totuus, joka johtaa konsensukseen.

\section{Konsensustavoidaanpitäärationaalisenatahdonilmauk- sena.Ideaalisessapuhetilanteessaparhaatargumentit jäävätvoimaan, koskaniitävoidaanjohdonmukaisim- min perustella(Habermas, 1987, 33, 112-113).}

Tämän näkökulman mukaan tulkintojen tekeminen on tieteen tehtävä. Tulkinnat ovat kielellisiä ilmauksia, joissa luodaan sarja uudenlaisia kielellisiä sääntöjä. Koska organisaatiot jatkuvasti luovat uutta kieltä saattaa tutkimuksesta tulla vain jo luotujen kielellisten sääntöjen toistamista. Tämän välttämiseksi kommunikatiivisessa toimintatutki- muksessa tutkimusprosessi ja kielen uudelleen luomisen prosessi liitetään toisiinsa. Tutkijat ja toimijat liitetään toisiinsa kielellisten, vuorovaikutukseen liittyvien siteiden kautta luomaan uutta kieltä ja uudenlaisia merkityssisältöjä (Gustavsen, 1992, 32-33).

Kommunikatiivisessa toimintatutkimuksessa uudenlaista kieltä ja uutta sosiaalista todellisuutta otetaan luomaan sellaisia ihmisryhmiä, jotka eivät aiemmin ole läpäisseet niitä asiantuntijamuureja, joiden kautta määritetään, ketkä voivat olla mukana luomassa todellisuutta; ketkä ovat diskurssin osanottajia.

\section{Organisaation kehittäminen}

Organisaation syvällisten muutosprosessien yhteydessä on demokraattisen dialogin oheen liitetty perinteisiä organisaation kehittämisprosesseja (ks. Honkasen artikkeli tässä lehdessä). Demokraattisen dialogin puitteissa on toteutettu aloitusseminaareja, työyhteisökohtaisia kehittämisprojekteja ja seurantaseminaareja. Näitä tukemaan on usein otettu mm. tiimivalmennusta tai ryhmädynaamisia prosesseja.

Organisaation kehittäminen ei ole selkeä metodinen tai teoreettinen koulukunta. Pikemminkin organisaation kehittäminen koostuu useista eri tieteiden alla ja eri maanosissa kehittyneistä koulukunnista, joita yhdistää väljästi tietynlainen arvotausta ja tietynlainen filosofia siitä, kuinka organisaation kehittämiseksi tulisi toimia. Organisaation kehittäminen ei myöskään ole niinkään joukko tekniikoita, kuin tietynlainen filosofia. Organisaation kehittämisen filosofisena ajatuksena on auttaa ihmisiä auttamaan itse itseään. Organisaation kehittämisessä nähdään ihmisten olevan perustaltaan terveitä ja heillä nähdään olevan omia motiiveja ja omia arvoja, joiden vapauttamisesta organisaation kehittämisessä on kyse (Schein, 1990, 14 ja Hanson \& Lubin, 1989, 16).

\section{Kultuurin muutos}

Kulttuuritutkimus on kolmas paradigman, jolla 
syvällisen kehittämisen prosesseja on tuettu. Kulttuurinäkökulmasta suoritettu tutkimus on jo verrattain vanhaa. Antropologit käyttivät kulttuurinäkökulmaa varsin syvällisessä merkityksessä tutkiessaan eri kulttuureita jo 1800-luvulla (Kroeber \& Kluchohn, 1952, 3 ja Bowles, 1989, 407). Kulttuurinäkökulma tuli organisaatiotieteisiin verraten myöhään. Selznick tunnisti 1950 -luvulla vuorovaikutuksen merkityksen organisaatioille (Selznick, 1968, 43) ja vasta 1970 ja 1980 -luvuilla kulttuurin tutkimuksesta tuli varteenotettava näkökulma organisaatiotieteessä (Smircich \& Calas, 1987, 230-231 ja Alvesson \& Berg, 1988, 22-25).

Kulttuurin tutkimisessa pyritään paljastamaan sosiaalisen käyttäytymisen taustalla olevien ajattelutapojen rikkaus ja tuomaan tulkinta organisaatiossa työskentelevien ihmisten tietoisuuteen heidän ymmärtämänsä kielen ja vertauskuvien avulla (McWhinney \& Batista, 1988, 54 - 55 ja Kreftig \& Frost, 1985, 160 - 162).

Kulttuurinäkökulma on klassillisesti jakautunut eri koulukuntiin: funktionaaliseen (Malinowski, 1969), strukturaalisfunktionaaliseen (RadcliffeBrown, 1968), kognitiiviseen (Markus \& Zajonk, 1985 ja Lord \& Foti, 1986), strukturaaliseen (LeviStrauss, 1977) ja symboliseen (Geertz, 1973).

Uudempi kulttuuritutkimus löi itsenä lävitse scheiniläisenä kulttuuritutkimuksena (Schein 1985), jota voidaan pitää strukturaalisesti painottuneena. Strukturaalisessa koulukunnassa tarkastellaan kulttuurin syvällisiä, alitajuisia ilmiöitä. Nämä alitajuiset kollektiiviset prosessit asettavat rajansa sekä mallinsa kieleen ja ajatteluun sekä sitä kautta kaikkiin yhteisössä esiintyviin normeihin, koko kulttuuriin (Levi-Strauss, 1977, 21-24 ja 68-71).

Aivan viime aikoina monet organisaationäkemykset (esimerkiksi postmodernit näkemykset) ovat olleet ns. post-strukturalistisia. $\mathrm{Ne}$ ovat saaneet vaikutteita konstruktivistisesti suuntautuneilta kulttuurinäkemyksiltä, esimerkiksi symboliselta interaktionismilta (Blumer 1986; Mead 1962).

\section{LOPUKSI}

Tässä artikkelissa on tarkasteltu tieteessä käynnissä olevaa paradigman muutosta ja sen heijastumista organisaatioihin ja niiden kehittämiseen. Varmaa perustaa etsivän tiedekäsityksen vähitellen korvautuessa paikallisuutta ja ihmisen maailmansisäisyyttä korostavilla näkökulmilla ovat myös käsitykset organisaatioista muuttuneet. Osaamisen yhteiskunnan kehittyminen ja postmodernien virtuaalisten verkosto-organisaatioiden esiinmarssi ovat myös vaatineet uudenlaisia näkökulmia. Organisaatioiden on selvitäkseen kyettävä uudistumaan syvällisesti. Tämä edellyttää dekonstruktiota. Perinteisesti organisaatiot ovat painottaneet tekemistä reflektiivisen keskustelun sijaan (Marshak 1998, 17-28).

Iduillaan oleva uudenlainen organisaatiotiede, jonka keinot ovat vielä eklektisiä, on alkanut vähitellen tunnistaa dekonstruktion merkityksen. Organisaatiotutkijat ovat tarkastelleet jo parikymmentä vuotta yhä lisääntyvästi kieltä ja tarinoita. Sosiaalista todellisuutta on jäsennetty monologisesta näkökulmasta (pääosin kulttuuritutkimuksessa), dialogisesta näkökulmasta (kuten demokraattisen dialogin menetelmässä) tai pluralistisesta näkökulmasta (josta Morganin mallit ovat ensimmäisiä esimerkkejä) (Grant \& Keenoy \& Oswick 1998, 7-12). Siirtymä pluralistiseen näkökulmaan on todennäköistä. Samalla organisaation kehittämisen menetelmät monimuotoistuvat ja erilaistuvat. On todennäköistä, että niissä kuitenkin tunnistetaan diskurssin merkitys ja pyritään dekonstruktioon.

A rtikkelissa kuvatut organisaation kehittämisen menetelmät poikkeavat toisistaan mm. omaamansa todellisuuskäsityksen suhteen. Vaikka kulttuuritutkimus edustaa modernin kritiikkiä, se ei ole luopunut perustan tai keskustan etsimisestä (Derrida 1997, 38-40). Myöskään habermasilaisittain painottunut demokraattinen dialogi ei ole luopunut modernin ihanteista (Pulkkinen 1998, 71). Perinteinen organisaation kehittäminen pitäytyy tiukasti modernin ihanteessa muutoin, paitsi paikallisuuden korostamisen suhteen. Paikallisuutta korostavat kuitenkin sitä radi- 
kaalimmin demokraattinen dialogi ja kulttuuritutkimus.

Vasta foucaultilainen genealogia irtoaa modernista. Genealogiassa esiintyy ajatus siitä, että minkä tahansa asian rakentamisen historiaa voidaan lähestyä olettamatta sitä alkuperäistä oliota, jolle tämä historia tapahtuu (Pulkkinen 1998, 96). Alkuperän katoaminen siirtää tarkastelun postmoderniksi. Derrida on radikalisoinut alkuperän etsimisen osoittamalla, että myös keskusta on moniäänistä diskurssia. Alkuperäistä täyttä läsnäoloa ei ole, vaikka länsimainen logosentrinen ajattelu on tuottanut täyden puheen illuusion. Derrida on dekonstruktionsa avulla siirtänyt keskustan samaksi merkkien leikiksi kuin muunkin diskurssin (Derrida 1997, 38-39 ja Hintsa 1998, 29).

$\mathrm{P}_{\mathrm{s}}$ ostmodernista näkökannasta kiinnostavimmaksi kysymykseksi organisaatioiden kehittämisessä nouseekin, kykeneekö ihminen muovaamaan uudenlaisen kielen ja uudenlaisen puheen suhteessa organisaatioihin? Me luomme kielen ja puheen avulla suhteen maailmaan ja olemme aina "heitettynä" maailmaan, kuten Heidegger sanoi. "Heitettynä" oleminen merkitsee, että oleminen on aina jo ymmärrettyä esiymmärryksemme pohjalta. Kieli ilmaisee ihmisen asettumisen maailmaan. Olemme myös sitoutuneet tiettyyn positioon keskustelussa, esimerkiksi organisaatiossa, emmekä voi helposti muuttaa kielipeliä tai liikkua kielipelistä toiseen.

\section{Ihmisten lïkkumavaraorganisaatiossaomaksutussa kielipelissänäyttäävähäiseltä. Sosiaalistumisessasaatu esiymmärrysjasepositio,johonmeidäton "puhuttu", asettavatmeidätkielenansaan, jostaonvaikeamurtau- tua ulos (Kupiainen 1997, 65-67).}

Muutoksessa on kysymys oman situaation muuttamisesta maailmaan. Uusi kieli ja uusi situaatio positioivat henkilön uudelleen. Tämä voidaan saada aikaan koulutuksellisen sivistyksen avulla. Mutta muuttuuko koko kulttuurinen kenttä, kaikkien toimijoiden positio suhteessa toisiinsa ja kaikkien yhteisesti käyttämä kieli?

Tällöin keskeiseksi nousee Foucaultin esittämä kysymys, kuka on oikeutettu käyttämään tiettyä kieltä? Missä paikoissa ja missä tilanteissa hänellä on oikeus puhua tiettyä kieltä? Onko vaietun ja puhumattomuuden murtaminen keino uudenlaisten merkityssisältöjen löytymiseen? Miten erilaisuuden kohtaamisessa oudon henkilön lähettämä merkitsijä kohtaa käyttäjiensä tuntemukset ja kulttuuriset valmiudet? Vaikka dekonstruktioita syntyisikin erilaisuuden kohtaamisessa tai uusien vertauskuvien käytössä, syntyykö uusia tarinoita, jotka antavat merkitystä ja energiaa toiminnalle? (Lehtonen 1996, 51, 109, 143)

Mm. nämä ovat kysymyksiä, joihin postmodernin organisaationäkökulman on koetettava vastata. Viime kädessä kysymys ei ole enemmästä eikä vähemmästä kuin ihmisen suhteesta maailmaan. Kyetäänkö ihmisiä päästämään ulos "maailmaan" lasista, jonka sisällä he Witgensteinin mukaan ovat? Hermeneutiikan vastaus on tulkinnassa, kun taas Nietzschelle jatkuva tulkinta merkitsee arvojen ja todellisen maailman kadottamista, nihilismiä. Vattimon mukaan kaikki palautuu kieleen, sillä vapaus on liikettä ilmiöiden välillä ja ilmiöt ovat tarinoita, joita ihmiskunta välittää kielessä ja symboleiden avulla (Vähämäki 1996, 267-283).

\section{LÄHTEET}

ALVESSON, M. \& Berg, P-O. (1988). Företagskultur och organisationssymbolism. Studentlitteratur. Lund.

Arbetsmiljöfonden. (1990). Utveckling genom diskussion. Stockholm.

BARRY, D. \& Hazen, M. (1996). Do You Take Your Body to Work? Kirjassa: Boje, D. \& Gephart, R. \& Thatchenkery, T. (eds.). Postmodern Management and Organization Theory. Sage. Thousand Oaks.

Van BEINUM, H. (1993). The Kaleidoskope of Workplace Reform. Kirjassa: Naschold, C. \& Gustavsen, B. \& van Beinum, H. Constructing the New Industrial Society. Arbetslivscentrum. Maastricht.

BERGER, P \& Luckman, T. (1994). Todellisuuden sosiaalinen rakentuminen. Gaudeamus. Helsinki. Alkup. 1996.

BINZARG, G. \& Manning, M. (1996). Reconstructions of Choice: Advocating a Constructivistic Approach to Postmodern Management Education. Kirjassa: Boje, D. \& Gephart, R. \& Thatchenkery, T. (eds.). Postmodern Management and Organization Theory. Sage. Thousand Oaks.

BION, W. (1961). Experiences in Groups. Tavistock Publications. Englewood Cliffs.

BLUMER, H. (1986). Symbolic Interactionism. Berkeley. BOJE, D. \& Fidzgibbons, D. \& Stengard, D. (1996). Storytelling in Administrative Science Quarterly: Warding the Postmodern Barbarians. Kirjassa: Boje, 
D. \& Gephart, R. \& Thatchenkery, T. (eds.). Postmodern Management and Organization Theory. Sage. Thousand Oaks.

BOWLES, M. (1989). Myth, Meaning and Work Organization. Organizational Studies 10/1989:3.

BRADSHAW, P. (1996). Women as Constituen Directors: RE-Reading Current Texts Using a Feminist-Postmodernist Approach. Kirjassa: Boje, D. \& Gephart, R. \& Thatchenkery, T. (eds.). Postmodern Management and Organization Theory. Sage. Thousand Oaks.

BURRELL, G. (1997). Pandemonium. Towards a RetroOrganization Theory. Sage. London.

BURREL, G. (1998). Modernism, Postmodernism and Organizational Analysisi: The Contribution of Michel Foucault. Kirjassa: McKinley, A. \& Starkey, K. Foucault, Management and Organization Theory. Sage. London.

CANTON, J. \& Kurland, N. (1996). A Theory of Stakeholder Enabling. Kirjassa: Boje, D. \& Gephart, R. \& Thatchenkery, T. (eds.). Postmodern Management and Organization Theory. Sage. Thousand Oaks.

CHIA, R. (1996). Metaphors and Metaphorization in Organizational Analysis: Thinking Beyond Thinkable. Kirjassa: Grant, D. \& Oswick, C. (eds.). Metaphor and Organizations. Sage. London.

CLEGG, S. (1990). Modern Organizations. Organization Studies in the Postmodern World. Sage. London

CLEGG, S. \& Gray, J. (1996). Metaphors in Organizational Research: Of Embedded Embryous, Paradigms and Powerfull People. Kirjassa: Grant, D. \& Oswick, C. (eds.). Metaphor and Organizations. Sage. London

CLEGG, S. (1998). Foucault, Power and Organizations. Kirjassa: McKinley, A. \& Starkey, K. Foucault, Management and Organization Theory. Sage. London.

DEETZ, S. (1998). Discursive Formations, Strategized Subordination and Selfsurveillance. Kirjassa: McKinley, A. \& Starkey, K. Foucault, Management and Organization Theory. Sage. London.

DERRIDA, J. (1988). Positioita. Gaudeamus. Helsinki. (Alkup. 1972).

DERRIDA, J. (1997). Rakenne, merkki ja leikki ihmistieteiden diskurssissa. Niin \& Näin 1/1997. (Alkup. 1966).

DUNFORD, R. \& Palmer, I. (1996). Metaphors in Popular Management Discourse: The Case of Corporate restructuring. Kirjassa: Grant, D. \& Oswick, C. (eds.). Metaphor and Organizations. Sage. London.

DÖHRMING, J. \& Gustafsson, R. (1990). Sälvlärande på Sjukvårdkliniken. Kirjassa. Arbetsmiljöfånden: Ut veckling genom diskussion. Stockholm.

DÖVING, E. (1996). The Image of Man: Organizational Action, Competence and Learning. Kirjassa: Grant, D. \& Oswick, C. (eds.). Metaphor and Organizations. Sage. London.

EHNINGER, D. \& Hauser, G. (1984) Commmunication of values. Kirjassa: Arnold \& Bowers (eds.): Handbook of Rhetorical and Communication Theory. Allyn and Bacon Inc. Boston.

EIJNATTEN, F. (1993). The Paradigm that Changed the Workplace. Arbetslivscentrum. Stocholm.

ELDEN, M. \& Levin, M. (1990). Cogenerative Learning. Bringing Participation into Action Learning. Kirjassa: Whyte, W. (ed.). Participatory Action Re- search. Newbury Park.

EPSTON, D. \& White, M. \& Murray, K. (1992). A Proposal for Re-Authoring Therapy. Kirjassa: McNamee \& Gergen (eds.). Therapy as Construction. Sage. London.

FLETCHER, B. (1990). Organization Transformation Theorists and Practitioners. Praeger. New York.

FOUCAUlT, M. (1977). Discipline and Punish. Penguin. Harmondsworth

FOUCAULT, M. (1998). Seksuaalisuuden historia. Gaudeamus. Tampere. Alkup. 1984.

GEERTZ, C. (1973). The Interpretation of Cultures. Basic Books. New York.

GEPHARD, R. \& Boje, D. \& Thatchenkery, T. (1996). Postmodern management and Coming Crises of Organizational Analyses. Kirjassa: Boje, D. \& Gephart, R. \& Thatchenkery, T. (eds.). Postmodern Management and Organization Theory. Sage. Thousand Oaks.

GERGEN, K. (1991). The Saturated Self. BasicBooks.

GRANT, D. \& Oswick, C. (1996). Getting the Measure of Metaphors. Kirjassa: Grant, D. \& Oswick, C. (eds.). Metaphor and Organizations. Sage. London.

GRANT, D. \& Keenoy, T. \& Oswick, C. (1998). Organizational Discourse: Of Diversity, Dichotomy and Multi-disclipninarity. Kirjassa: Grant, D. \& Keenoy, T. \& Oswick, C. (eds.). Discourse + Organization. Sage. London.

GUSTAVSEN, B. (1990). Vägen till bättre arbetsliv. Arbetslivscentrum. Stockholm.

GUSTAVSEN, B. (1992). Dialogue and Development. Arbetslivscentrum. Maastricht.

HABERMAS, J. (1987). Järki ja kommunikaatio. Helsinki.

HANSON, P. \& Lubin, B. (1989). Answers to Questions Freguently Asked about Organization Development. Kirjassa: Sikes \& Drexler \& Grant (eds.). The Emerging Practice of Organization Development. University Associates. San Diego.

HASSARD, J. (1996). Exploring the Terrain of Modernism and Postmodernism in Organization Theory. Kirjassa: Boje, D. \& Gephart, R. \& Thatchenkery, T. (eds.). Postmodern Management and Organization Theory. Sage. Thousand Oaks.

HINTSA, M. (1998). Mahdottoman rajoilla. Tutkijaliitto. Helsinki.

HOPPER, T. \& Macintosh, N. (1998). Management Accounting Numbers: Freedom on Prison - Geneen versus Foucault. Kirjassa: McKinley, A. \& Starkey, K. Foucault, Management and Organization Theory. Sage. London.

HUSA, S. (1995). "Foucalt'lainen metodi“. Niin \& Näin. 3/1995

INNS, D. \& Jones, P. (1996). Metaphor in Organization Theory: Following in the Footsteps of the Poet. Kirjassa: Grant, D. \& Oswick, C. (eds.). Metaphor and Organizations. Sage. London.

JACKSON, N. \& Carter, P. (1998). Labour and Dressage. Kirjassa: McKinley, A. \& Starkey, K. Foucault, Management and Organization Theory. Sage. London.

JUUTI, P. (1995). Johtaminen ja organisaation alitajunta. Otava ja Aavaranta-sarja. Keuruu.

JUUTI, P. \& Lindström, K. (1995). Postmoderni ajattelu ja organisaation syvällinen muutos. JTO-tutkimuksia sarja ja Työ ja ihminen tutkimusraportti. Helsinki. 
JUUTI, P. \& Varjoranta, T. (1993). Johtaminen, organisaatio ja yhteistoiminta metalliteollisuudessa. Työpoliittinen tutkimus no 39. Helsinki.

KREFTING, L. \& Frost, P. (1985). Understanding Webs, Surfing Waves, and Wildcatting. Kirjassa: Frost \& Moore \& Louis \& Lundberg \& Martin (eds.). Organizational Culture. Sage. Newbury Park.

KROEBERG, A. \& Kluchohn, C. (1952). Culture. A Critical Review of Concepts and definitions. Published by the Museum. Gambridge.

KUHN, T. (1970). The Structure of Scientific Revolutions. The University of Chigago Press. Chigago. (Ensipainos 1962).

KUPIAINEN, R. (1997). Kielessä asumme. Kieli eettisyyden pelitilana. Kirjassa: Mälkiä, M. \& Stenvall, J. (toim.). Kielen vallassa. Tampere University Press. Tampere.

LAX, W. (1992). Postmodern Thinking in a Clinical Practice. Kirjassa: McNamee \& Gergen (eds.). Therapy as Construction. Sage. London.

LEHTONEN, M. (1996). Merkitysten maailma. Vastapaino. Tampere.

LEVI-STRAUSS, C. (1977). Structural Antropology 1. Peregrine Books. Suffolk. Ensip. 1963.

LEVY, A. \& Merry, U. (1986) Organizational Transformation. Praeger. New York.

LORD, R. \& Foti, R. (1986). Schema Theories, Informtion Processing, and Organizationla Behavior. Kirjassa. Sims \& Gioa. The Thinking Organization. San Francisco.

LYNCH, M. (1993). Scientific Practice and Ordinary Action. Cambridge University Press. Cambridge.

LYOTARD, J - F: (1985). Tieto postmodernissa yhteiskunnassa. Vastapaino. Jyväskylä.

MALINOVSKI, B. (1969). A Scientific Theory of Culture and Other Essays. London. (Ensip. 1944).

MANGHAM, I. (1996). Some Consequences of Taking Gareth Morgan Seriously. Kirjassa: Grant, D. \& Oswick, C. (eds.). Metaphor and Organizations. Sage. London.

MARKUS, H. \& Zajonk, R. (1985). Cognitive Perspective in Social Psychology. Kirjassa: Lindsey \& Aronson (eds.). Handbook of Social Psychology. Random House. New York.

MASHAK, R. (1998). A Discourse on Discourse: Redeeming the Meaning of Talk. Kirjassa: Grant, D. \& Keenoy, T. \& Oswick, C. (eds.). Discourse + Organization. Sage. London.

McKINLEY, A. \& Starkey, K. (1998). Managing Focault: Foucault, Management and Organization Theory. Kirjassa: McKinley, A. \& Starkey, K. Foucault, Management and Organization Theory. Sage. London.

McKINLEY, A. \& Starkey, K. (1998). The 'Velvety Grip': Managing managers in the Modern Corporations. Kirjassa: McKinley, A. \& Starkey, K. Foucault, Management and Organization Theory. Sage. London.

McKINLEY, A. \& Taylor, P. (1998). Trough the Looking Glass: Foucault and the Politics of Production. Kirjassa: McKinley, A. \& Starkey, K. Foucault, Management and Organization Theory. Sage. London.

McNAMEE, S. \& Gergen, K. (1992). Johdanto. Kirjassa: McNamee \& Gergen (eds.). Therapy as Construction. Sage. London.

McWILlEY, W. \& Batista, J. (1988). How remythologization Can Revitalize Organizations. Organizational Dynamics. 1988. 17.
MEAD, G. (1962). Mind, Self and Society. Chicago. (Ensip. 1934).

MINTZBERG, H. (1983) Structure in Fives. Prentice Hall International. Englewood Cliffs

MORGAN, G. (1980). Paradigms, Metaphors, and Puzzle Solving in Organizational Theory. Administrative Science Quarterly 25 (4).

MORGAN, G. (1986). Images of Organization. Sage. Newbury Park.

MORGAN, G. (1989). Creative Organization Theory. Sage. Newbury Park.

MORGAN, G. (1993). Imaginization. New Mindsets for Seeing, Organizing, and Managing. Sage. Thousand Oaks.

PIHLSTRÖM, S. (1996). Tieteenfilosofian jättiläiset vastakkain. Niin \& Näin. 3/1996.

PORRAS, J. \& Silvers, R. (1991). Organization Development and Transformation. Annual Review of Psychology 42.

PULKKINEN, T. (1998). Postmoderni politiikan filosofia. Gaudeamus. Tampere.

RÄFTEGÅRD, C. (1990). Metoder i LOM-projectet. Arbetslivscentrum. Stocholm.

SAVAGE, M. (1998). Discipline, Surveillance and the 'Career'. Kirjassa: McKinley, A. \& Starkey, K. Foucault, Management and Organization Theory. Sage. London.

SCHEIN, E. (1985). Organizational Culture. San Francisco.

SEIDMAN, S \& Waner, D. (eds.). (1992). Postmodernism \& Social Theory. Blackwell. Oxword.

SELZNICK, P. (1968). Modern organisationsteori. Stockholm.

SHOTTER, J. (1993). Converstional Realities. Constructing Life through Language. Sage. London.

SMIRCICK, L. \& Calas, M. (1987). Organizational Culture. Kirjassa: Jablin \& Putnam \& Roberts \& Porter (eds.) Handbook of Organizational Communication. Sage. Newbury Parks.

STARKEY, K. \& McKinlay, A. (1998). Deconstructing Organization - Discipline and Desire. Kirjassa: McKinley, A. \& Starkey, K. Foucault, Management and Organization Theory. Sage. London.

WEISBORD, M. (1988). For More Productive Workplaces. Journal of Management Consultation 4/ 1988:2.

Von WRIGHT, G. H. (1987). Tiede ja ihmisjärki. Keuruu. 1987.

VÄHÄMÄKI, J. (1996). Gianni Vattimon radikaalin hermeneutiikan merkitys yhteiskuntateorialle. Kirjassa: Rahkonen, K. (toim.). Sosiologian teorian uusimmat virtaukset. Gaudeamus. Tampere.

Artikkeli on saapunut toimitukseen 3.8.1998. Se on hyväksytty julkaistavaksi 23.11.1998. 